\title{
Gregorio Marañón: \\ Constructor de tolerancia y reconciliación
}

\author{
Sergio Arturo Cañas López \\ Departamento de Salud Pública, \\ Universidad Centroamericana "José Simeón Cañas", \\ San Salvador, El Salvador
}

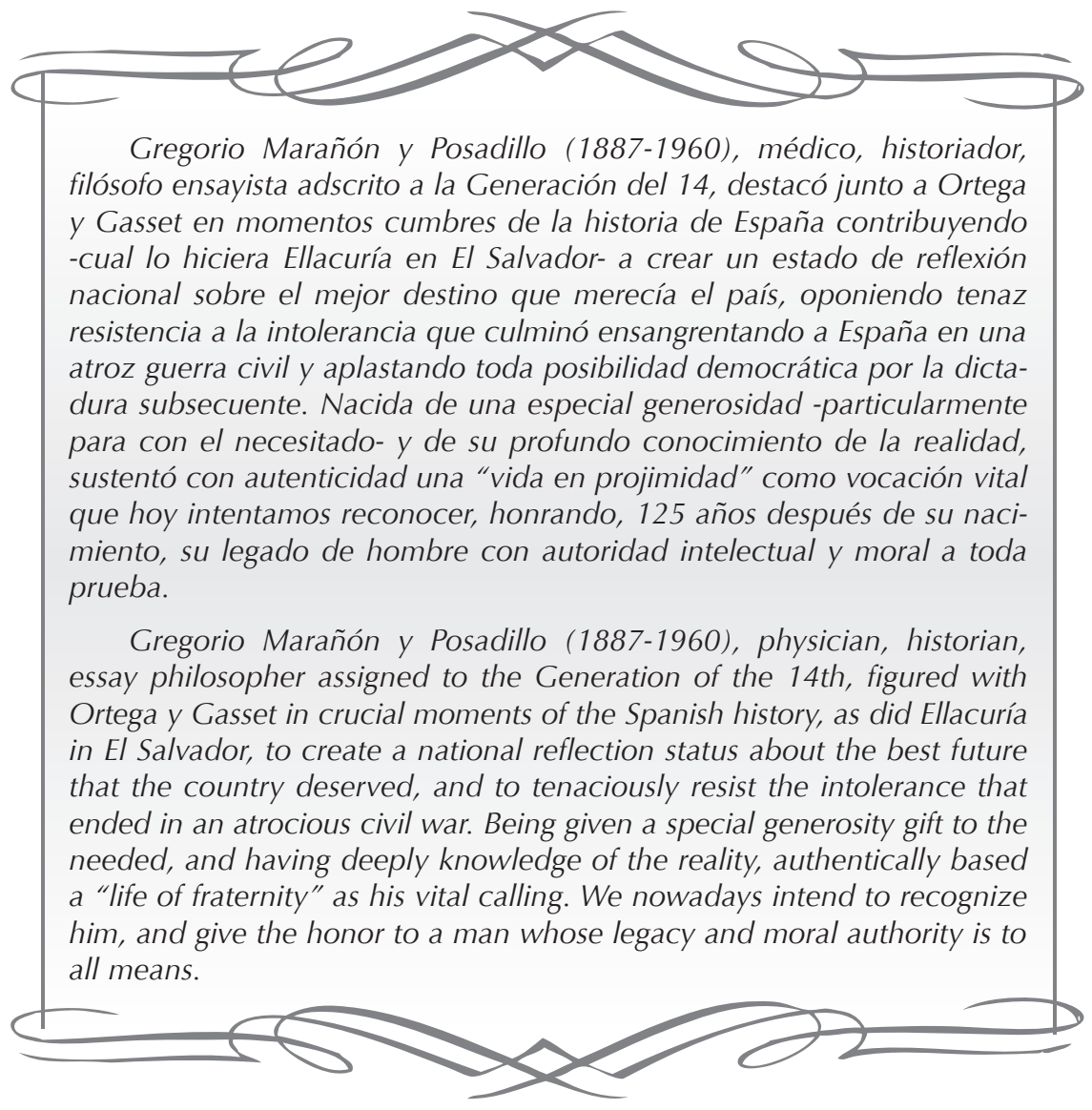


C i el pasado cuenta, es por lo que significa para nosotros. Es producto de nuestra memoria colectiva, es en suma, el tejido fundamental sobre el cual erigimos nuestro presente. Nos ayuda a comprender mejor la sociedad en la que vivimos hoy, a saber qué defender y preservar, a saber también qué derribar y cambiar; porque la historia no es historia, si no constituye desde el hoy una relación activa con el pasado. ${ }^{1}$ Pero el presente no necesita del pasado sino en relación con el porvenir, porque sólo así es lograble la reivindicación del pasado, su reconquista para el día de mañana. No en balde se ha dicho que la historia es un profeta con la mirada vuelta hacia atrás.

Teniendo éstas por premisas, abordar a Gregorio Marañón como paladín de la tolerancia y la reconciliación nacional de la España de su tiempo debe, para ser un tema de fecunda reflexión, llevarnos a anclar esa tolerancia y reconciliación en el aquí y ahora de un mundo que aún muestra a diario la intolerancia desmedida que es aún capaz de mostrarnos sus más horrorosas consecuencias de dolor, sufrimiento y muerte.

\section{La generación del I4 y su contexto}

Novecentismo o Generación del 14 son las denominaciones genéricas de una estética principalmente literaria que agrupa a un conjunto de autores, en su mayoría ensayistas, ${ }^{2}$ situados entre la Generación del 98 y la Generación del 27.

Los elementos característicos que han de concurrir para identificar la existencia de una generación y afirmar que ésta existe como realidad histórica, permiten señalar que en los hombres y mujeres de una generación han de darse las siguientes condiciones, que son reconocibles en la generación a la que se adscribe Gregorio Marañón y que sucintamente enumeraremos: ${ }^{3}$ a. El nacimiento en torno a una fecha específica: se trata de que a varios hombres, la común circunstancia de nacer en torno a un mismo año los coloca frente a un hecho exterior importante, aproximadamente a la misma edad.

b. La coincidencia de elementos formativos, que les permitían estar bien dotados de importante formación intelectual.

c. Las relaciones entre iguales: los miembros de una generación se hallan requeridos por las mismas preocupaciones $y$ afectados por las mismas diferencias $y$ afinidades humanas. 
d. La rectoría de uno de sus miembros: en toda generación, la figura de uno de sus integrantes se erige como conductora del amplio grupo histórico. Esta figura es Ortega y Gasset para la generación del 14 .

e. Un lenguaje generacionalmente compartido: para un escritor, el lenguaje es su sangre, su latido humano. Cuando este latido colectivamente se convierte en una actitud vital, ciertas palabras, hasta un estilo de la expresión, desde el vocabulario a la sintaxis, comienzan a constituir el patrimonio de esa generación.

f. La parálisis de la generación anterior: mientras un grupo humano no asume frente al que le precede una actitud vital, éste sigue proyectando su propia actitud, prolongándola más allá del marco histórico de su edad. Cuando una generación nace con genuina existencia propia, es que la anterior ya no conserva aquellas fuerzas de creación que la hacían vivir.

Con ello en mente, no requiere gran sagacidad crítica para observar que hacia 1910 comienza a producirse cierto cambio de tono en la literatura española. Esa mudanza es plenamente perceptible hacia 1914, para señalar una fecha que entra en la historia del mundo con el gran estruendo de la Primera Guerra Mundial, que es la culminación de un largo proceso político-social con múltiples manifestaciones en España y en el mundo entero. Así las cosas, un cruzado viento de hechos e ideas contribuyó al citado cambio de tono, dando el nuevo acento a la generación que hoy comentamos convirtiéndose en expresión clara de una notable eclosión intelectual.

De hecho, desde los años iniciales del siglo XX se habían acusado las manifestaciones de la crisis -expresadas hasta con violencia- entre diversos sectores de la sociedad; particularmente en España, ésta incluye hechos especialmente trágicos y convulsos ante los que las esferas culturales e intelectuales se sintieron fuertemente conmovidas; de hecho, la fecha del 13 de octubre de 1909 marca un hito sangriento en el proceso de la vida nacional con el fusilamiento del maestro laico Francisco Ferrer y Guardia $^{4}$ en el foso de Santa Amalia de la prisión de Montjuic. Ferrer recogió la tradición moderna iniciada con Rousseau en el S. XVIII -contraria a la autoridad y a la cosmovisión religiosa- para adaptarla al libre pensamiento que florecía para entonces en las ciudades industriales. Este proyecto práctico de pedagogía libertaria, le acarreó la enemistad con los sectores conservadores y la Iglesia católica de la época, que veían en la así Ilamada "Escuela Moderna" una amenaza a sus intereses. ${ }^{5}$ Ello marcó para muchos el inicio de una atmósfera enrarecida por la intolerancia. ${ }^{6}$ 
Así las cosas, llevado en buena medida por el esquema ideológico que gobernó la formación intelectual de los miembros de su generación, en parte también impulsado a ello por la misma circunstancia política y social que puso marco a los años de su madurez, Gregorio Marañón cumple con los que considera inexcusables deberes de ciudadanía, inmiscuyéndose en un mundo donde no siempre los intelectuales han conseguido hacer realidad sus idearios, sus sueños previamente elaborados en el artificial clima de su mundo mental.

En al menos dos concretos momentos-cumbres se hizo Ilamativa realidad el destacado protagonismo político de Gregorio Marañón; corresponde el primero a los años de la dictadura; pertenece el segundo al crucial momento en que la Monarquía, desasistida por casi todos, abre paso a la Segunda República. Importa conocer, aunque de modo sumario, la trama de ambos episodios, a lo cual nos dedicaremos más adelante además de consignar otros momentos, tal vez menos divulgados, de Marañón como hombre público preocupado por la realidad social que veía con profunda consternación.
De momento baste señalar que los principales escritores de esta generación tienen así motivo para sus más fecundas preocupaciones a las que abordan desde una destacada preparación intelectual que les conduce a escribir libros doctrinales y ensayos en los más diversos campos, lo cual les permitió construir con sin igual maestría el tríptico: literatura, ciencia y filosofía. ${ }^{8}$

Precisamente la ciencia dio de sí para esta Generación del 14 al menos a seis connotados médicos que, junto a su fecunda labor científica, descollaron también como hombres de letras y pensadores de fecunda impronta filosófica. Ciertamente, podría escribirse un interesante capítulo de la literatura, ciencia y filosofía españolas y en él habrían de figurar: Santiago Ramón y Cajal (1852-1934), Ramón Turró y Darder (1854-1926), Roberto Novoa Santos (1885-1933), Augusto Pi Suñer (1879-1965), Gustavo Pittaluga Fattorini (1876-1956), coronándose esta lista de pensadores eminentes con Gregorio Marañón y Posadillo (1887-1960) ${ }^{9}$, a quien hoy homenajeamos.

\section{Gregorio Marañón: la vocación, la generosidad y la noción del otro}

Establecer una mejor valoración de la tolerancia y la reconciliación en Marañón pasa por destacar previamente tres aspectos de singular importancia. Ciertamente, debe el análisis ser detenido en el concepto de vocación, en la noción de "el otro" y en la generosidad derivada de ella que destacan al hoy homenajeado. 
A propósito de la vocación, consigna Julián Marías: "Hay siempre una dimensión de la persona que es la más próxima a nosotros mismos, lo que podríamos Ilamar él centro de ordenación' de nuestra vida entera, capaz de organizar y configurar en torno suyo todo lo demás, y así darle puesto y sentido. Es el núcleo o esquema de nuestra vocación, el fondo insobornable, aquello que mejor expresa lo que hemos querido ser, lo que a última hora explica lo que hemos sido. Es aquel lado o aspecto nuestro con quien más radicalmente nos entendemos" ${ }^{\prime 10}$

Si bien Marañón la entendía como "voz interior que nos Ilama hacia la profesión y el ejercicio de una determinada actividad", también matizaba el concepto señalando que: "Todos Ilevamos dentro -escribe en 1934, prologando la obra póstuma de Roberto Novoa Santos- una personalidad más compleja que la que indica nuestra fachada oficial. Aun en el caso en que hayamos acertado con nuestra verdadera vocación, una tendencia oculta $-y$ a veces más de una- nos empuja a servir en silencio a preocupaciones que no son las que nos sirven para ganarnos el pan y para catalogarnos en los padrones profesiones" ${ }^{11}$

En este sentido, acota Cortés, ${ }^{12}$ Marañón fue "vocación en sí". Mas no todos canalizamos nuestra diaria tarea con vocación. A veces, intuimos que no es la nuestra; de otras existe la certeza de que estamos en el camino. ¿Cómo descubrir, entonces, cuál es nuestra vocación? ¿De qué instrumentos habremos de servirnos principalmente para saberlo? De dos que resultan infalibles: la espontaneidad y el desinterés. Porque la vocación no se impone, ni es objeto de tráfico y porque el desinterés es la faceta primogénita de las grandes obras, es el aliciente de la perseverancia y el acicate del deber cumplido.

La vocación, la gran mayoría de las veces, se encuentra orientada hacia determinada asignatura $u$ oficio; sin embargo, puede ser tal su poderío, arrastrar con tal pujanza, que los frágiles diques que enmarcan un arte o una ciencia, cualquier disciplina, se rompen: la vocación se desborda y se sublima; es energía que sólo se transforma, no se crea ni se destruye; es frente de norte amplio y de horizonte ancho; y la vocación no se encuentra acá o allá. Entonces, existe algo más, la vocación de ser y estar, la vocación de vivir. Y Marañón fue eso: permanentemente vocación de vivir. ${ }^{13}$

Descubrir la vocación, es comenzar. Ejercitarla y perfeccionarla, es continuar. Tres rutas nos conducen hacia su cotidiano ejercicio y su firme perfección: la veracidad, la comprensibilidad y la ecuanimidad -afirma Cortés-. ${ }^{14}$

La verdad, como norma de conducta, debe ser brújula en el 
ejercicio vocacional e ingrediente insustituible de su perfección consecuente. La veracidad es el camino inequívoco del conocerse a sí mismo. Lo contrario debe segregarse como un estigma, como un mal hábito. La veracidad traduce el comportamiento de la íntima honestidad, por lo tanto, ha de ser legítima y sin artificios. Como la verdad siempre representa un argumento, su férrea solidez y su estructura químicamente pura son basamentos a favor de una vocación que se ejercita con pulcritud y dignidad. ${ }^{15}$

Otro elemento indispensable en el ejercicio de la vocación es la comprensibilidad. Es éste el compás de espera de la veracidad, podríamos decir que es su tabla de mandos, es la puesta a punto de aquélla. ${ }^{16}$

Veracidad y comprensibilidad son componentes de una trilogía en la cual el tercer elemento -según hemos dicho ya- es la ecuanimidad. Tal vez sea ésta la más difícil de valorar, porque exige una revisión al desnudo del candidato garante de la vocación que ha de ponerse a prueba. ${ }^{17}$

Finalmente -acota Cortés- "creo sería inoficioso, añadir algo más, para expresar cómo se debe de amar una vocación, especialmente la de Gregorio Marañón, que fue prédica fértil de su vocación más liberal: la vocación de vivir". ${ }^{18}$

La noción "del otro", por su parte, complementa los criterios para ponderar con justicia la vocación de tolerancia y reconciliación manifiesta en Marañón.

Ciertamente, si algo está en el fondo de la relación médicopaciente es el encuentro con otro hombre, con un hombre sufriente que dio pie a las reflexiones más penetrantes que Marañón y otros -Laín Entralgo entre ellos- hicieron para llegar a constituir exhaustivos estudios filosófico-antropológicos sobre el "otro". Precisamente esa relación de convivencia con "el otro" durante el ejercicio de la medicina -identificada por Laín bajo el neologismo de "vida en projimidad"19-, esa ayuda activa y desinteresada al otro, fue la que cultivó Marañón por los últimos cincuenta años bien cumplidos de vida profesional.

El renombre profesional de Gregorio Marañón se lo granjeó tanto por su sólida formación científica, como por la posesión de una innata cualidad de empatía que dieron virtuosismo a la vida del médico; consciente de la importancia de ello, había de decir Marañón en su libro Vocación y ética: "Los médicos tenemos para curar un arma fija, que es la ciencia, arma cada vez más poderosa, pero con ella sola, la utilidad de nuestra actuación se reduciría a términos casi miserables. Mas en torno a esta eficacia segura y controlable, en torno de nuestras recetas de efecto matemático, actuamos sobre el hombre dolorido por la vía invisible e imponderable 
de la sugestión". Años más tarde, en 1945, prologando la Antología de escritos del profesor García Tapia, añade el ser de verdad "un gran médico", que estriba en "el amor invariable al que sufre y la generosidad en la prestación de la ciencia, que han de brotar en cada minuto, sin esfuerzo, naturalmente, como de un manantial... Sólo así se es dignamente médico, con la idea clavada en el corazón de que trabajamos con instrumentos imperfectos y con medios de utilidad insegura, pero con la conciencia cierta de que hasta donde no puede llegar el saber llega siempre el amor"; $;{ }^{\prime 2}$ amor a ese prójimo sufriente al que llamamos paciente.

"Tenía a la cabecera del enfermo un don bastante poco frecuente: el de inspirar confianza plena y absoluta con brevísimas palabras, con ademán sucinto. Tras esta misteriosa influencia había un secreto que su gran prestigio no bastaba a explicar. Quizá fuese su gran bondad", señala Granjel. No en balde decía también Marañón que el instrumento que más progresos había conquistado para la medicina era la silla del consultorio, pues nada reemplaza el valor técnico de saber hablar y escuchar con el paciente, así sea la era de la más moderna: era biotecnológica; ${ }^{21}$ seguramente de ahí venga la idea del escultor José Chillida de esculpir una suerte de sillón para evocarle colocándolo en un altozano del cigarral de Dolores. $^{22}$
Es esa "vida en projimidad", aludida ya por Pedro Laín, marcada por la beneficencia, benedicencia y benefidencia, es decir por la buena voluntad, palabras animadoras y actos de confianza en la relación con el enfermo, la que junto a la vocación, como hábito radical de la existencia humana, hicieron en Gregorio Marañón que su existencia fuera sólo un medio a su gran proyecto de vivir, como bien lo acota Guillermo Cortés.

Julián Marías, por su parte, señaló siempre de Marañón esa vida "en projimidad" de manera magistral al consignar: "Marañón lo dio todo, su generosidad o prodigalidad le hizo dar todo: su atención, su consejo, su elogio, su ciencia, su afecto, su admiración, su respeto y su tiempo. Dio la riqueza de su vida, una jornada de casi veinte horas diarias durante medio siglo, para verterlas sin reserva a España y a quienes lo necesitaran. Lo que Marañón guardaba para sí, su casa, sus libros, sus cuadros, sus personas queridas, aquel cigarral que miraba hacia Toledo, era sólo la intimidad necesaria para conservar esa riqueza y poder seguir dándola". ${ }^{23}$

Corolario de lo antes dicho en torno a la generosidad de Marañón, Julián Marías atinadamente ha señalado: "si me pidieran decir en sólo tres palabras lo que los españoles hemos perdido con la muerte de Don Gregorio, yo diría que el poder llamar a Marañón. Esta expresión 
significaba su enorme disponibilidad y cómo era sentida por quien le necesitara. Marañón en tantos órdenes era una instancia a la que siempre se podía recurrir. Se con- taba con él porque tenía prestigio auténtico, autoridad personal y una bondad cuyos límites costaba encontrar ${ }^{\prime \prime 2}$.

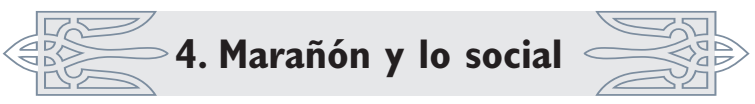

Pedro Laín Entralgo al respecto señala que el ansia de justicia social es, todo el mundo lo sabe, una de las máximas ideas-fuerza de nuestro tiempo; en modo alguno nuestro homenajeado fue ajeno a estas ansias de justicia.

Marañón fue -continúa Laínmédico, escritor y hombre de España, denunciando multitud de veces la injusticia social que en torno a sí veía. Ante todo, como tal médico; luego, como simple ciudadano, dio irrefutables pruebas de ello, algunas de las cuales -recordadas por Laín en el décimo aniversario de la muerte de don Gregorio-, son las siguientes: $:^{25}$

$1^{\circ}$. La campaña con que protestó, en nombre de la medicina y de la justicia social, contra las deplorables condiciones en que entonces eran asistidos muchos enfermos del Hospital General de Madrid.

$2^{\circ}$. La hermosa y patética denuncia que en uno de sus mejores libros médicos - La edad críticahizo de las penosas consecuencias que la miseria y la rudeza del trabajo cotidiano de tantas y tantas campesinas españolas suelen dejar en su aspecto y en su biología.

$3^{\circ}$. La crítica rigurosamente "social" que como médico y como español supo hacer de la alimentación de los españoles: "En España -escribía hace como cuarenta años-, la buena mesa era privilegio de unos cuantos elegidos de la fortuna. No se ha sentido, entre nosotros, la ausencia de la democracia en ningún aspecto de la vida nacional, como en el comer".

$4^{\circ}$. Su solidaridad con Baroja en el grito de protesta social que, además de ser una espléndida obra novelesca, fue la trilogía $L a$ lucha por la vida. Aquellas tres novelas, dice Marañón, recordando el impacto que sobre su alma produjo la primera lectura de la serie, "fueron como tres brechas abiertas en la ceguera egoísta de los burgueses incomprensivos, por las que irrumpieron las hordas famélicas de pan y amor... A partir de estas novelas, el ansia de renovación social cobra en la juventud española ímpetu y carácter". 
$5^{\circ}$. Desde un punto de vista puramente clínico, su práctica y su regla de tratar a los enfermos de hospital "como si fuesen cabaIleros de la Tabla Redonda".

$6^{\circ}$. El nervio mismo de su tan discutida aparición en la vida política española: el hecho de sentirse a sí mismo más como "reformador social" que como "republicano", en el sentido meramente político de esta palabra -así lo proclamó él en su casi olvidado, pero enormemente significativo prólogo al libro ¿A dónde va España?, de Marcelino Domingo (acaecía esto en diciembre de 1929)-, y la no menos significativa fórmula de su más personal objeción contra la Segunda República española, a la que él veía menos socialista de lo que debía ser y, por otro lado, torpemente liberal. $7^{\circ}$. El tono y el contenido -típicamente gorkianos- de sus artículos "Sobre la represión de la mendicidad", "Los muertos de hambre", "El veraneo de los niños pobres" y otros semejantes.

$8^{\circ}$. Su expresiva semblanza del médico socialista Jaime Vera ${ }^{26}$ y la impresión de honda solidaridad con los obreros a propósito de una manifestación del primero de mayo -la de 1920- que destila su artículo "El consuelo del dolor".

Basten éstos para mostrar y demostrar que la dimensión de "lo social", como ahora tantas veces se dice, no faltaba en el "patriotismo del tiempo" -la fidelidad cordial e intelectual al tiempo en que se vive-, que tan certeramente supo formular y tan profundamente supo vivir el hombre Gregorio Marañón.

\section{Gregorio Marañón: vocación de tolerancia y reconciliación}

Marañón, aún adolescente o a las puertas de su madurez, aprendió la lección que nunca olvidó: la de la tolerancia como norma ideal de conducta. Dos figuras contribuyeron fundamentalmente a ello: Pérez Galdós y Menéndez y Pelayo. ${ }^{27}$ Muy importante en la creación de esta mentalidad fue la personificación exacta de la misma en las actitudes discrepantes, pero con tendencia al entendimiento, que ofrecieron Galdós y Menéndez y Pelayo en sus vibrantes discusiones. Dicho talante de entendimiento basado en la comprensión de las ideas del otro fue permeando a Marañón en el núcleo intelectual y formativo que anteriormente se ha citado. De hecho, Palacios García Cervigón. ${ }^{28}$

Para Marañón, así como para todos y cada uno de la Generación del 14, existe una misión común, un mandato sentido como espiritual tarea que no hay medio de esquivar: ninguno pudo sentirse ajeno a la realidad dolorosa de la patria. 
La preocupación por el futuro de España, el dolor ante su presente, el interés por la revalorización de su pasado, se hacen en Marañón una responsabilidad moral marcada por el respeto y la tolerancia hacia las ideas de los demás, la comprensión como pauta de actuación y la defensa de la libertad como valor humano esencial, pilares sobre los que descansó su liberalismo, del cual señaló en 1946 a propósito de sus "Ensayos Liberales" que: "El liberalismo, es pues, una conducta $y$, por tanto mucho más que una política. $Y$, como tal conducta, no requiere profesiones de fe, sino ejercerla de un modo natural, sin exhibirla ni ostentarla. Se debe ser liberal sin darse cuenta, como se es limpio, o como por instinto, nos resistimos a mentir".

Movido por ello, Marañón, hizo manifiesta su abierta oposición al gobierno del General Primo de Rivera, cuando, como tantos otros intelectuales de su tiempo, adoptaron una postura contraria a la acción política y social de la dictadura; motivos concretos que trajeron como inicial consecuencia de tal actitud la destitución de Marañón, en 1926, de la presidencia del Ateneo. ${ }^{29} \mathrm{Su}$ proximidad intelectual y personal con Miguel de Unamuno hizo que el cese de éste en sus cargos universitarios y su destierro ahondasen el enfrentamiento de Marañón con la dictadura. En 1925, su desacuerdo con la política sanitaria de Martínez-Anido tuvo como consecuencia su destitución como director del Hospital del Rey y, poco después, el que su nombre figurara, con el de los generales Weyler, Aguilera y Batet y el del conde de Romanones, entre otros, falsamente implicado como partícipe de la famosa 'Sanjuanada', concluyendo la aventura en un inicial encarcelamiento por un mes y la imposición de sanción económica de 100,000 pesetas. ${ }^{30}$

Relatando el suceso afirma el conde de Romanones que: "El que ni de cerca ni de lejos tuvo relación ninguna con los elementos que acabo de nombrar- hace referencia a los verdaderos protagonistas de la 'sanjuanada' - fue el doctor Marañón, a pesar de lo cual por ello fue procesado, ingresó en la cárcel y multado." El doctor Enrique Suñer, en su libro Los intelectuales y la tragedia española, recuerda cómo en "la campaña para sacar a Marañón de la Cárcel Modelo, iban recogiendo firmas por todas partes", de quienes no dudaron en respaldarlo ${ }^{31}$.

Algunos años después y en coyuntura crucial para la vida española, en que el régimen monárquico -sentenciado ya por los mismos que se llamaban sus defensores- es suplantado por la experiencia republicana, Gregorio Marañón torna a representar el papel distinguido. Encabezó con José Ortega y Gasset y Ramón Pérez de Ayala el grupo de intelectuales al servicio de la 
República, y al aludir, en prólogo fechado en 1946, a tal episodio de su vida de hombre público, escribe Marañón: "Se produjo una fisura, que cada día se ahondaba, entre la vida oficial y esas otras fuerzas, las del espíritu y las sociales: las que, sin garrulería de frase hecha, se pueden llamar las 'fuerzas vivas' de un país... Una parte de los estudiosos, de los creadores de aquellos años críticos se alejaron de la Monarquía." El conde de Romanones, en sus Memorias ya citadas, relata cómo gobernando Berenguer, apenas derrocada la dictadura, pronunciaron discursos -de 'eficacia destructora' los califica- Ortega y Gasset, Marañón y Pérez de Ayala. En el propio domicilio de Marañón, añade nuestro último informante, tuvo la transacción en que vino a consumarse el cambio de régimen; "cuando yo -cuenta Romanones-, por encargo del rey, flameé en casa del doctor Marañón la bandera blanca, todo había terminado y de la Monarquía sólo quedaba un cosa: el recuerdo" ${ }^{32}$

Efectivamente en enero de ese año (1930), al terminar la dictadura primorriverista, Marañón era uno de los principales referentes intelectuales del momento. Hombre respetado por la inmensa mayoría de los protagonistas de aquella hora, se convirtió en adalid del movimiento republicano. Con la crisis de la monarquía, fundó e impulsó, junto a José Ortega y Gasset y Ramón Pérez de Ayala, la Agrupación al servicio de la República, plataforma que auspició la llegada del régimen republicano de $1931 .{ }^{33} \mathrm{En}$ esta coyuntura es conocida la decisiva reunión que se celebró en su despacho el 14 de abril, en donde el conde de Romanones y Niceto Alcalá-Zamora pactaron la transición de la monarquía a la república y la salida de Alfonso XIII de España. La ascendencia social y política de Marañón hizo que figurase entre los candidatos a la presidencia de la Segunda República. En la política republicana tuvo un papel destacado. Elegido diputado para las Cortes Constituyentes que elaboraron la Constitución promulgada en diciembre de 1931, en diversas ocasiones renunció a ofrecimientos para formar gobierno o ser ministro. La paulatina radicalización e intransigencia de la vida política española, le llevó a alejarse del primer plano político renunciando a su escaño en mayo de $1933 .{ }^{34}$

En los meses finales de la Segunda República, al advertir la extraordinaria radicalización política y el ascenso de la violencia a la que se estaba asistiendo desde finales de 1934, Marañón realizó constantes Ilamamientos a la responsabilidad, a la comprensión, al respeto de la normalidad democrática y a la concordia civil. A diferencia de otros intelectuales que le eran afines, en los meses inmediatamente anteriores a la Guerra Civil, confiaba en el futuro de la República y achacaba la inestabilidad política y social 
existente a la inmadurez pasajera del régimen de $1931^{35}$.

Efectivamente, había necesidad de arbitrar nuevos elementos de solución para acelerar la llegada de una pacificación urgente, ya que aunque ambas partes creyeron al inicio que podían llegar a triunfar, cada vez quedaba más claro que el supuesto triunfo no podía resultar pronto, ni fácil y que la prolongación del conflicto resultaría inaceptable a juzgar por sus costos. Ese era el momento en que España reclamaba a la Generación del 14 su contribución en la construcción de una salida audaz a la crisis, denominándose a este esfuerzo la construcción de la Tercera España ${ }^{36}$.

De hecho, existía en el país un grupo, aglutinado en torno a la Generación del 14, cuya importancia social y política era quizás mucho mayor que la que alcanzaron a expresar en los años inmediatos anteriores al conflicto abierto. Cobró este grupo conciencia exacta de la coyuntura, de su fuerza y de sus posibilidades para poner su poder de democratización al lado de los mejores destinos nacionales con una pronta y estable salida a la tragedia nacional y supo aumentar su convicción de que, si se deja el destino patrio en manos de una polarización en aumento, el conflicto no tendría solución razonable ni justa; rehuir a este esfuerzo por des-escalar el conflicto y superar la crisis era abdicar a un imperativo histórico.
Pusieron en marcha una suerte de estado de reflexión nacional ya que llegaron a reconocer que los trabajos de los mejores estudiosos de la crisis que atravesaba la nación no podían ser efectivos sin llegar a formar parte de la conciencia nacional. ${ }^{37}$

La Tercera España, nombre que acuñaron para referirse a su esfuerzo, no era una nueva organización política para situarse entre las dos partes en conflicto, sino que era un intento de organización formalmente social -y no formalmente políticaque se ocuparía de los intereses del país sin pretender el poder político. No nace tampoco para ser correa de transmisión de otra fuerza, dado que no admite ser condicionada para el logro de sus fines. Para conseguir todo esto, se podía echar mano de los medios más diversos, solo excluidos los violentos. No estaban en capacidad de usarlos y el sólo hecho de intentar su uso propiciaría su autodestrucción.

Sin embargo, a pesar de los esfuerzos de reconciliación, ya en el último año de vida de la República, Marañón se siente agobiado por una constante inquietud, quizás adivinando el espesor de la tragedia que se cierne sobre España. Acaecida la muerte de Calvo Sotelo, la inseguridad por su vida y por la de los suyos resulta clara, al igual que para varios de los que constituían la Generación del 14. A partir del 20 de julio de 1936, decide buscar co- 
bijo en la Residencia de Estudiantes de la Calle del Pinar donde se le da asilo y protección a un nutrido número de intelectuales españoles; y en una improvisada mezcla de barracones y hospital se instalan, entre otros, Ortega y Gasset, Dámaso Alonso y Menéndez Pidal y el mismo Gregorio Marañón. España se desangra en una guerra civil de costos humanos sociales, económicos y científico-culturales de dimensiones que son muestra irrefutable de la especial dureza de las guerras civiles en particular; tal ensañamiento era cuestión que Marañón advertía con extraordinaria claridad.

Respecto de la especial dureza de las guerras civiles, son señalados como elementos que propenden a favorecer una especial acritud entre los bandos en contienda el hecho de que al comienzo de los enfrentamientos los combatientes aún viven entremezclados, de lo que resulta un conocimiento profundo de las cualidades del adversario que explica la específica vulnerabilidad de ambos bandos. Es precisamente la perversa explotación de este conocimiento lo que aporta a las hostilidades civiles un rasgo especialmente infame. De hecho quien está bien familiarizado con el sentido del honor y deshonor de su rival, puede, al pisotear estos principios, infringirle -además de perjuicios externos- profundas heridas anímicas, de forma que una prolongada e intencionada humillación recíproca genera progresivamente un crecien- te odio imborrable a punto de aborrecer al enemigo lo que es asumido como máxima que deja su impronta en los bandos en conflicto. ${ }^{38}$

Es probable que el conocimiento de ello (y el presentimiento de las dimensiones que adquiriría el conflicto) por parte de Marañón quedará plasmado de forma extraordinaria cuando escribió a Marcelino Domingo: "Me consterna esta lucha que desangra a nuestro pueblo, porque en el otro lado, hay pueblo también" ${ }^{39}$ o en aquella otra de sus frases celebres "El médico, en la guerra, es el único que no quiere matar, el único para quien no existe el enemigo, porque no hay enemigo capaz de esconderse dentro de un hermano". ${ }^{40}$

De hecho, el tributo de sangre en la contienda fue extraordinariamente alto. España para entonces tenía alrededor de 25 millones de habitantes y en apenas 3 años que duró el conflicto abierto, se estiman según diversos cálculos entre 150,000 hasta 500,000 muertos. Mes a mes fue cada vez más evidente que la guerra civil española era una "guerra total" en el sentido de que no hacía ninguna diferencia entre militares y civiles, pues cada vez más civiles eran víctimas de las acciones militares, los bombardeos, las represalias. El terror estatal hizo lo suyo. En este contexto, resulta simbólico el bombardeo y destrucción de Guernica. ${ }^{41}$ 
La dictadura gobernó desde el principio con mano de hierro; se trataba de provocar una clara ruptura con el pasado, no sólo se trató del fin de la revolución en la zona republicana sino de la eliminación definitiva de la herencia y tradición liberal y republicana, era donde los vencedores veían el auténtico sentido de la guerra civil ganada. ${ }^{42}$

Sobre todo, de lo que se trataba para los vencedores era de eliminar a todos sus opositores (los efectivos y los potenciales). Por eso el número de personas que fueron víctimas de asesinatos políticos y judiciales fue, después de 1939, extraordinariamente alto: según datos oficiales españoles, a fines de 1939 fueron a prisión 270,000 personas, además de más de 100,000 a campos de concentración y batallones de trabajo. Gabriel Jackson deduce que la represión masiva en el territorio dominado por los nacionales ocasionó hasta finales de la Segunda Guerra Mundial de 150,000 a 200,000 víctimas con o sin condena de un tribunal militar. Aunque no existen cifras exactas -que por otra parte tampoco cambiarían la valoración histórica de los crímenes de Franco en la posguerra-, puede decirse sin dudarlo que la venganza de los vencedores en los primeros años de posguerra alcanzó un punto álgido único en la historia española. ${ }^{43}$

También el exilio que tuvieron que sufrir cientos de miles pertenece a la realidad social de la España de Franco y hay que valorarlo como un aspecto particular de la política de represión. La gran ola de refugiados se vertió sobre Francia, donde los exiliados, en campos de recepción montados a toda prisa, soportaron más bien el penoso destino de prisioneros que el de asilados políticos. Datos oficiales del Ministerio de Interior francés hablaban de 441,000 españoles que habrían cruzado la frontera de los Pirineos hasta abril de 1939. Puesto que muchos no volvieron pronto, Manuel Tuñón de Lara estima en 300,000 el número de exiliados, otros autores hablan de 162,000 emigrantes de larga duración. Aunque servicios de socorro organizados precipitadamente pudieron evacuar antes del asalto alemán sobre Francia una cantidad considerable de republicanos hacia Latinoamérica, éstos tuvieron que sufrir mezquindades y reservas hostiles que impidieron una óptima organización de la ayuda. Muchos republicanos fueron entregados a Franco por el gobierno de Vichy o las fuerzas de ocupación alemanas. Miles de republicanos españoles lucharon en el maquis, donde encontraron la muerte, decenas de miles no sobrevivieron a los campos de concentración alemanes (sobre todo Mauthausen). ${ }^{44}$

Particularmente desoladoras fueron las consecuencias ideológicas y psicológicas de la guerra. La derrota de 1939 marcó en los actos y la conciencia política de la población obrera, sobre todo en los terri- 
torios rurales, una profunda fractura histórica y dejó tras de sí un trauma que afectó la vida obrera de muchas zonas (especialmente de Andalucía) hasta el final del franquismo. Las consecuencias despolitizadoras de este trauma sólo pudieron superarse paulatinamente en el transcurso de los años setenta. ${ }^{45}$

La supuesta política de reconciliación de Franco no llegó en todos los "años de paz" -tan rimbombantemente estilizados- a conceder a los perdedores de la guerra civil una amplia amnistía general; sólo hubo algunas amnistías individuales -proclamadas espectacularmentefranquearon el camino a la libertad a algunos escogidos cuidadosamente. La temible represión de los años cuarenta al perseguir, torturar, fusilar y exiliar a aquellos que habían apoyado (a conciencia o porque no les quedó ninguna otra posibilidad) la república del Frente Popular, profundizó aún más los abismos existentes. Los amos del poder no pensaron después de 1939 en una reconciliación; ellos querían ante todo la venganza. El primero de abril -el día que se declaró el fin de la guerra civil- no fue un "día de la paz"; en la época de Franco fue más bien conmemorado como "día de la victoria" con el que año tras año se recordaba a los españoles la división del país en vencedores y vencidos. ${ }^{46}$
La arrogancia de los vencedores y la humillación de los sometidos provocó que la supervivencia de una identidad libertadora y republicana en España sólo fuera posible en la clandestinidad o el exilio. La dura dictadura de Franco destruyó después de 1939 todos los símbolos de la libertad y los monumentos republicanos, eliminó las celebraciones obreras o las manipuló (por ejemplo el $1^{\circ}$. De mayo), arruinó las tradiciones proletarias y liberales, en suma: impidió el mantenimiento y cultivo público de una identidad republicano-democrática.

Marañón regresó a España en el otoño de 1942. Si bien la dictadura -como hizo con otros intelectuales- intentó utilizar su figura para mejorar su imagen exterior, Marañón asumió la tarea de recuperar la tradición liberal que el régimen de Franco trató de erradicar. ${ }^{47}$ Él, por su parte, se dedicó afanosamente a dar reiterados testimonios a favor de la reincorporación de los exiliados a la vida española: la amistosa cercanía que mantuvo con muchos de ellos, sus ayudas a todos los perseguidos que acudieron él, su intervención en el homenaje que la universidad tributó a Ortega y Gasset tras su fallecimiento y sus declaraciones críticas hacia la dictadura en la prensa extranjera conformaron una conducta liberal excepcional en aquellos tiempos. 
Relanzar el concepto de tolerancia legado por Marañón pasa por señalar que la tolerancia, como todo constructo social, es histórica y contingente, es decir, las motivaciones y criterios que la definen $y$ dan sentido varían con el tiempo y la cultura. De hecho, mientras en su origen el término designaba una actitud de permisividad con respecto a las creencias religiosas o metafísicas del otro, actualmente su significado ha derivado hacia el terreno ideológico y de opinión política. Recordemos que etimológicamente proviene del verbo latino tolerare, que significa sufrir, llevar con paciencia o soportar. ${ }^{48}$ Marañón estuvo desde su tiempo más cercano hacia aquellas posturas que abogan por una redefinición de la tolerancia como algo positivo, como una actitud que nos permite aceptar y comprender al otro en su alteridad, paso ineludible para llegar a valorar precisamente esa diferencia como elemento de riqueza para la construcción de un espacio público democrático y de entendimiento común a través del convivir, en concordancia plena con la conocida frase de Américo Castro: "La convivencia consiste en existir colectivamente en el plano de lo hecho mutuamente posible" ${ }^{49}$

Ciertamente un 16 de noviembre, pero de 1995, por iniciativa de la UNESCO y de las Naciones Unidas, es proclamada esa fecha como el "Día Internacional de la Tolerancia", conmemorándose además con ello el cincuentenario de las dos organizaciones, ocasión en la que los signatarios destacaron que la tolerancia activa (distinta de concesión, condescendencia o indulgencia) no es sólo una virtud individual o un principio moral sino también una necesidad política y jurídica para individuos, grupos y Estados con el propósito de conservar la paz, la democracia y el desarrollo sosteni$b e^{50}$. Es decir, si definimos aquello que debe tolerarse, eso implica que otras cosas deben ser intolerables. Como afirma Gimeno Sacristán: "La tolerancia no sólo obliga a renunciar, sino a ser beligerantes en la defensa contra todo aquello que amenace a otros bienes de interés para todos y a la tolerancia misma es uno de ellos". ${ }^{51}$

Así, inequidad, extrema pobreza, creciente quiebre de estructuras familiares, fragilidad de instituciones democráticas, carácter excluyente de los nacionalismos, contribuyen a crear tensiones sociales y son muestras de intolerancia ante las cuales hay que facultar a los individuos para que asuman como actitudes vitalicias las responsabilidades de diálogo, respeto mutuo, no violencia, pluralismo; en suma, tolerancia activa que exige justicia, solidaridad e imparcialidad para superar toda forma de exclusión y discriminación. 
Construir una cultura de tolerancia activa en el presente es tarea de cardinal importancia sobre todo en el marco de la sociedad neoliberal que tan nefastas consecuencias está trayendo al mundo de los valores y la convivencia democrática, sobre todo asentadas en el pragmatismo exacerbado ("todo se vale"), la competitividad y el individualismo feroz, el consumismo, la superficialidad reflexiva, la tolerancia entendida como ausencia de compromiso y orientación, etc.

Hoy en el mundo entero urge sumarnos todos en la construcción de una cultura de tolerancia activa, tarea en la que todos -absolutamente todos- cuentan para lograr ser exitosos. Nos comprometen en ese esfuer-

\section{Notas}

1 Chesneaux, J., ¿Hacemos tabla rasa del pasado? A propósito de la historia y de los historiadores, Siglo XXI editores, México, 2005.

2 Fernando Aínsa al reseñar la tesis doctoral de Dagmar Vandeboch, La ensayística de Marañón en la entreguerra española, señala que el ensayo, como género bisagra entre la historia y la reflexión, cruce entre teoría y praxis, ha privilegiado el contenido sobre la forma y la misión ética del autor sobre cualquier consideración estética. Cubre un espectro que puede ir del ensayo formal -histórico, sociológico, científico, crítico, literario- al más informal, impresionista y periodístico, según el énfasis que se le da a uno u otro. Género camaleónico, Juan Marichal hablaba de su "libertad camaleónica", género híbrido y poli- zo personas que nos han marcado su impronta en ese camino, sean estos Marañón, Luther King, Mandela, Menchú, Gandhi, Monseñor Romero y Ellacuría, quienes por la defensa de la tolerancia sufrieron agresión, persecución, cárcel e incluso muerte por las fuerzas de la intolerancia, cegadas por la arrogancia y el desprecio por la vida misma.

Honrar ese legado de los ya citados, hombres y mujeres de todos, depositarios de autoridad moral e intelectual a toda prueba, debe mover nuestras fibras afectivas y nuestro pensamiento lúcido hacia una perseverante, fecunda y audaz construcción de una cultura de la tolerancia activa y la reconciliación nacional, que tanta falta nos hacen.

morfo, el ensayo se vincula a períodos de crisis y cambio, más que a épocas dominadas por sistemas no cuestionados, tanto estéticos como ideológicos. Tradicionalmente es considerado como el más representativo e idóneo para reflejar la plural y compleja realidad española de ese entonces (Rilce 24.2, 2008).

3 Chabás, J., Literatura española contemporánea 1898-1950, Colección Verbum Mayor, Editorial Verbum, pp. 6-8.

4 Ibíd., p. 260

5 Wikipedia. La enciclopedia Libre: "Francisco Ferrer y Guardia. Biografía", Disponible en: http://es.wikipedia. org/wiki/Francisco_Ferrer_Guardia.

6 Más en rigor, en los años 30 llegó a su ápice un período convulso de la historia de España, cuyo origen puede situarse 
con la agitación de la gran huelga revolucionaria de agosto de 1917, período que desemboca en la dictadura de Primo de Rivera en 1923.

7 Sánchez Granjel, L., Gregorio Marañón. Su vida y su obra, Cap. I: "Historia de una vida", Ediciones Guadarrama, Madrid, 1960.

8 La España de los años 30 se nos presentaba como un país vitalista. El tono de la vida madrileña lo daba en buena medida la Puerta del Sol, "el foro de la ciudad", decía Baroja, "donde hervía la multitud de día y de noche”; allí se comentaban noticias, se citaba a la gente, se conspiraba, se vendían periódicos, décimos de lotería, se organizaban manifestaciones, se hacían negocios...". El ambiente de tertulias prestaba -por su parte- un tinte peculiar a la vida española, al punto de señalarse que no podía reconocerse ninguna otra institución más característicamente española que la tertulia. Tenían tan alto nivel intelectual y literario que se constituyó en el espacio de intensa actividad en la que la Generación del 14 expresaba con pasión su preocupación por España y su fecunda producción intelectual y literaria.

9 Chabás, J., Opus cit., "Médicos ensayistas", pp. 316-317.

10 Marías, J., Los Españoles. “¿Quién es Gregorio Marañón?”, Revista de Occidente, Madrid, 1962, pp. 191-200.

11 Sánchez Granjel, L., Opus cit., Cap XI: "La obra literaria".

12 Cortés, G. A., Algo sobre Gregorio Marañón, Editorial Ahora, San Salvador, El Salvador, 1978, Pág.10. Es de destacar que lo acotado por el médico salvadoreño Guillermo A. Cortés tiene especial valor pues recoge un consistente perfil de Marañón construido a partir de los años que compartió la afortunada circunstancia de ser su discípulo y cercano compañero de trabajo, lo que le convierte, como pocos en El Salvador, en un referente obligado para quienes estudian a Marañón.

13 Ibíd., p. 11

14 Ibíd.

15 Ibíd.

16 Ibíd.

17 Ibíd., p. 12

18 Ibíd., p. 15

19 Sánchez Torres, F.:"Aproximación a Pedro Laín Entralgo".

Disponible en: http:/wwww.encolombia.com/medicina/academiamedicina 23357

20 Sánchez Granjel, L., Opus cit., Cap. IV: "El Profesional".

21 Ibíd.

22 Solera, P., "Un médico de oídas. El científico que diagnosticaba a los pacientes escuchándoles", El País.com, publicado el 8/05/1987.

23 Marías, J., Opus cit., pp. 191-200.

24 Ibíd.

25 Laín Entralgo, P., "Marañón y "Lo Social", Boletín de Patología Médica, marzo, 1970, pp. 123-124.

26 Jaime Vera López (Salamanca 1859-Madrid 1918) fue un político socialista español, nacido el 20 de mayo en una familia de ideología republicana. Muy joven se traslada a Madrid donde con 15 años inicia la carrera de medicina finalizando sus estudios con sobresaliente y premio extraordinario en 1879. Fue discípulo del doctor Esquerdo en el Hospital General de Madrid donde fundó el gabinete electro terapéutico. 
Es considerado uno de los fundadores de la psiquiatría moderna en España. Junto a su notable interés por el respeto por los discapacitados psíquicos y por el trato humano a los enfermos, su actividad política le llevó a pertenecer desde 1877 al grupo prefundacional del PSOE. Fue el primero en sugerir la colaboración con los republicanos y sus diferencias a este respecto con el resto del grupo hizo que temporalmente abandonara su participación hasta 1890, año en el que participara en la elaboración del primer manifiesto electoral del PSOE, así como en las primeras celebraciones del $1^{\circ}$ de mayo en España.

27 Sánchez Granjel, L., Opus cit., Cap. XI: "La Obra Literaria".

28 Palacios García Cervigón, G., "La influencia intelectual de Marañón: Benito Pérez Galdós", en Herreros, B., Gargantilla, P.; Bandrés, F. (Coords.), Gregorio Marañón: Cumbre y sintesis para el siglo XXI, Colección Docencia Universitaria, Serie Humanidades Médicas, Fundación Gregorio Marañón/Fundación Tejerina, Unidad Docente, 2008.

29 Ibíd.

30 Lope Vega, A., Bibliografía de Gregorio Marañón, Biblioteca del Instituto Antonio de Nebrija de Estudios sobre la Universidad, Universidad Carlos III de Madrid (2009), p. 21.

31 Sánchez Granjel, L., Opus cit., Cap. I: "Historia de una vida".

32 Ibíd.

33 La lucha a muerte mantenida por los intelectuales españoles para propiciar la modernización del país bien merecía su participación en las directrices de la república que se estaba perfilando y en el duro camino que tendría que recorrer. Su única preocupación es que la transición sea ordenada, no esté sujeta a intereses partidistas y que cuente con los consejos de los hombres de letras. A sus filas se unen principalmente estudiantes e intelectuales, y como nace como "una leva en masa contra la Monarquía" más que como un partido político en regla, atrajo a muchas personas pertenecientes a otros partidos. Quince días después de su fundación cuenta con 15,000 miembros y en abril alcanza los 25,000. Hasta su disolución en octubre de 1932, en esos veinte meses de vida, Ortega ejerce la dirección de un instrumento político al que profesa una entrega total.

34 Lopez Vega, A., Opus Cit., p. 22.

35 Ibíd., p. 23.

36 Es de destacar la similitud de este esfuerzo que, aún con sus distancias, es posible reconocer con los esfuerzos conducidos académico-intelectualmente por Ignacio Ellacuría desde la Universidad Centroamericana "José Simeón Cañas" (UCA), en momentos en que la solución de la Guerra Civil en El Salvador era advertida como imperativa para poner fin al conflicto armado en medio del cual fuera martirialmente asesinado un 16 de noviembre de 1989, junto a sus compañeros jesuitas y dos de sus colaboradoras.

37 La contribución en este sentido de Ellacuría y la UCA resultaron invaluables, tomando cuerpo en los más diversos medios de divulgación académica de la universidad, particularmente en ECA 437 (noviembre, 1986) y 443 (mayo, 1987) y en los medios de opinión pública nacional e internacional.

38 Waldmann, P. y Reinares, F. (comp.), Sociedad en guerra civil: Conflictos violentos en Europa y América Latina, Ediciones Paidos América, Barcelona, 1999. 
39 "Autopsia a Marañón en el 50 aniversario de su muerte", en http://www. larazones/noticia/8860-autopsia-amarañon

40 Gregorio Marañón: de Wikiquote: la colección libre de citas y frases célebres, Disponible en: http:// es.wikiquote.org/wiki/Gregorio_Marañón

41 Bernecker, W. L., "Reconstrucción y comparación de los efectos de las Guerras Civiles estadounidenses y española", en Waldmann, P. y Reinares, F. (comps), Sociedades en Guerra Civil. Conflictos violentos en Europa y América Latina, Paidós Ibérica, 1999.

42 Ibíd.

43 Ibíd.

44 Ibíd.

45 Ibíd.

46 Ibíd.

47 Lopez Vega, A., Opus cit., p. 24.
48 Vila Merino, E., "Educar para la tolerancia, educar para la convivencia", en Espiral. Cuadernos del Profesorado 2 (4), 43-47, disponible en: http://www. cepcuevasolula.es/espiral

49 Sotelo Vásquez, A., "Américo Castro y la Generación del 14", en Cuadernos Hispanoamericanos No. 426, pp. 29-50, 1985.

50 Organización de las Naciones Unidas para la Educación, la Ciencia y la Cultura (UNESCO, 1995): "Declaración de principios sobre la Tolerancia". $28^{\mathrm{a}}$. Reunión de la Conferencia General, París, 25 de octubre al 16 de noviembre 1995. Citado por Cañas López en "La Construcción universitaria de una cultura de Tolerancia activa: un legado más de nuestros mártires", San Salvador, 15 de noviembre de 2005 .

51 Gimeno Sacristán, J., Educar y convivir en una cultura global, Madrid, Morata, 2001. Citado por Vila Merino, E., en "Educar para la Tolerancia, educar para la convivencia". 